\title{
Four hydrogen-bonding motifs in oligonucleotides
}

\author{
Noriaki Minakawa, Kazuyuki Kuramoto, Sadao Hikishima, and Akira Matsuda* \\ Laboratory of Medicinal Chemistry, Graduate School of Pharmaceutical Sciences, \\ Hokkaido University, Kita-12, Nishi-6, Kita-Ku, Sapporo 060-0812, Japan \\ E-mail: matuda@pharm.hokudai.ac.jp
}

\begin{abstract}
The design and synthesis of imidazo[ $\left.5^{\prime}, 4^{\prime}: 4,5\right]$ pyrido[2,3-d]pyrimidine nucleosides and 1,8-naphthyridine $C$-nucleosides with the aim of developing new base pairing motifs consisting of four hydrogen bonds is described.
\end{abstract}

Keywords: Nucleoside, C-nucleoside, imidazopyridopyrimidine, 1,8-naphthyridine, hydrogen bond, thermal stability, oligonucleotide

\section{Contents}

1. Introduction

2. Construction of imidazo $\left[5^{\prime}, 4^{\prime}: 4,5\right]$ pyrido[2,3-d]pyrimidine nucleosides 2.1. Synthesis of imidazole 2'-deoxyribosides from 2'-deoxyinosine

2.2. Synthesis of imidazo $\left[5^{\prime}, 4^{\prime}: 4,5\right]$ pyrido[2,3-d]pyrimidine nucleosides

3. Thermal stability of the DNA duplexes containing base parings between the imidazopyridopyrimidine bases

4. Desing and synthesis of 1,8-naphthyridine $C$-nucleosides

5. Thermal stability of the DNA duplexes containing base parings between the naphthyridine and the imidazopyridopyrimidine bases

6. References

\section{Introduction}

DNA is the storage and carrier of genetic information in all living organisms, and generally forms a right-handed double helix with a complementary DNA molecule. The structure of the DNA double helix is based on the Watson-Crick hydrogen bonding (H-bonding) of adenine:thymine (A:T pair, two H-bonds) and guanine:cytosine (G:C pair, three H-bonds) base pairings. ${ }^{1}$ 
H-bonding interaction plays a critical role in not only conserving and transmitting genetic information but also in double helix stability. Consequently, much attention has been devoted to the synthesis of artificial oligodeoxynucleotides (ODNs) including unnatural nucleobases, which could form a more stable, higher-ordered structure with DNA, RNA and protein, or DNA itself, with application to biochemistry, biotechnology, and medicinal chemistry. In contrast to the research directed toward thermally stable base pairing between natural and unnatural nucleobases, few studies have been reported on the possibility of alternative base pairing consisting of new H-bonding motifs. For example, Benner et al. proposed new base pairing, that is, 6-aminopyrazin-2-one: 5-aza-7-deazaisoguanine ( $\mathrm{V}: \mathrm{J})$, isoguanine: isocytosine (isoG:isoC), and 2,6-diaminopyrimidine: 1-methyl-pyrazolo[4,3-d]-pyrimidine-5,7(4H,6H)-dione (k:p) base pairs (Figure 1), and investigated their enzymatic incorporation into DNA and RNA with the aim of "extending the genetic alphabet. ${ }^{2}$
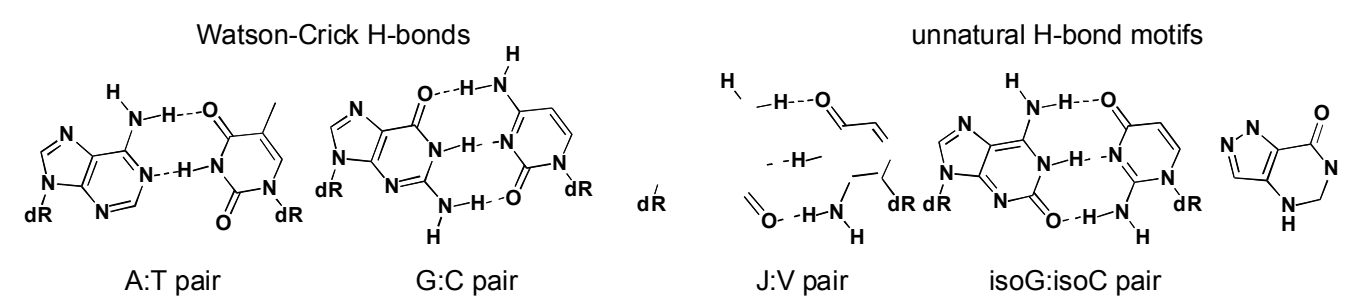

Figure 1. Watson-Crick hydrogen-bonds and examples of unnatural hydrogen-bonds.

We envisioned a new base-pairing motif, which would be more thermally stable than the Watson-Crick H-bonding. We proposed new base pair combinations consisting of four H-bonds, imidazo[5',4':4,5]pyrido[2,3-d]pyrimidine-4,7(5H,6H)-dione $\quad\left(_{i} \mathbf{O}^{\mathbf{O}}\right): \quad$ 4,7-diamino imidazo[5',4':4,5]pyrido[2,3-d]pyrimidine $\quad\left({ }_{i} \mathbf{N}^{\mathbf{N}}\right)$ pair and 4-aminoimidazo-[5', $\left.4^{\prime}: 4,5\right]$ pyrido[2,3-d]pyrimidine-7(6H)-one $\quad\left({ }_{i} \mathbf{N}^{\mathbf{O}}\right): \quad$ 7-aminoimidazo[5',4':4,5]pyrido $\quad[2,3-d]$ pyrimidine-4 $(5 H)$-one $\left({ }_{i} \mathbf{O}^{\mathbf{N}}\right)$ pair, which are called to be first generation four H-bonding motifs as shown in Figure 2. ${ }^{3}$ 

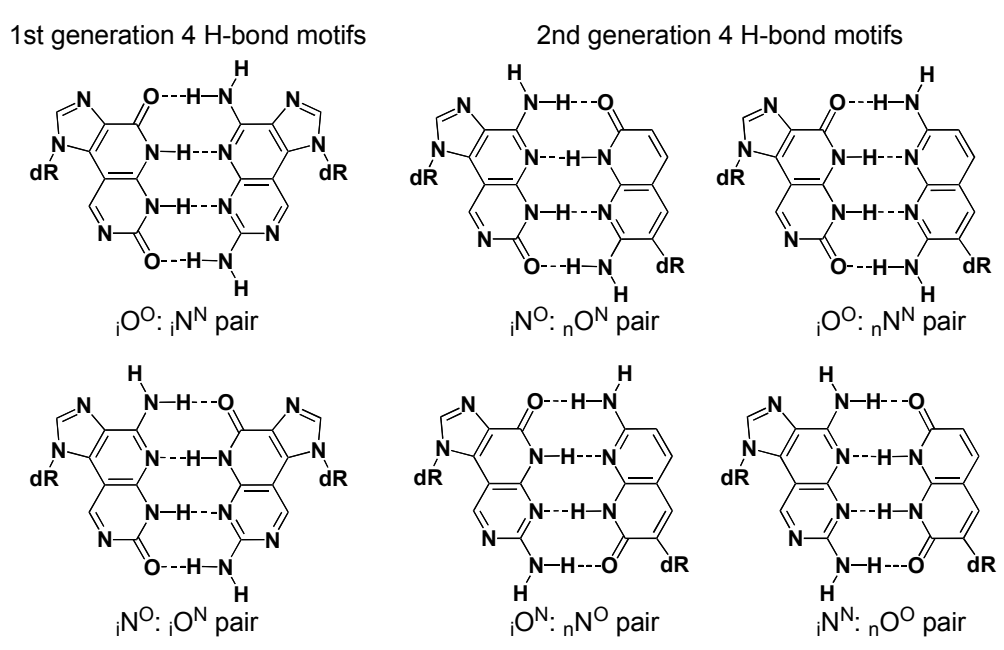

Figure 2. Four hydrogen-bonding motifs.

As second generation motifs, we also designed four sets of naphthyridine:imidazopyridopyrimidine pairs, $\quad{ }_{\mathbf{i}} \mathbf{N}^{\mathbf{O}}: 3$-substituted 2-amino-7hydroxy-1,8-naphthyridine $\left({ }_{n} \mathbf{O}^{\mathbf{N}}\right)$ pair, ${ }_{i} \mathbf{O}^{\mathbf{N}}: 6$-substituted 2-amino-7-hydroxy-1,8- naphthyridine $\left({ }_{n} \mathbf{N}^{\mathbf{O}}\right)$ pair, ${ }_{i} \mathbf{O}^{\mathbf{O}}:$ 2,7-diamino-1,8-naphthyridine $\left.{ }_{\left({ }_{n}\right.} \mathbf{N}^{\mathbf{N}}\right)$ pair, and ${ }_{i} \mathbf{O}^{\mathbf{O}}$ : 2,7-dihydroxy-1,8-naphthyridine $\left({ }_{\mathbf{n}} \mathbf{O}^{\mathbf{O}}\right)$ pair. ${ }^{4}$ These motifs were re-designed to satisfy shape complementarity resembling a pyrimidine:purine base pair in natural DNA. In this report, we summarize the synthesis of these nucleosides and the results of thermal stability when these nucleosides are incorporated into complementary positions of ODNs.

\section{Construction of imidazo[5',4':4,5]pyrido[2,3- $d]$ pyrimidine nucleosides}

\subsection{Synthesis of imidazole 2'-deoxyribosides from 2'-deoxyinosine}

The most straightforward synthesis of the desired nucleosides was thought to be through intramolecular cyclization of the 5-pyrimidinylimidazole nucleosides, which would be prepared from the Stille coupling reaction of a 5-iodoimidazole nucleoside with an appropriate tributylstannylpyrimidine. The 5-iodoimidazole nucleosides can be synthesized from 2'-deoxyinosine derivative $1 .^{5}$ The synthesis of the 5-iodoimidazole nucleosides $\mathbf{4 a}$ and $\mathbf{4 b}$ was first carried out as shown in Scheme 1. The 2'-deoxyinosine derivative $\mathbf{1}$ was treated with 1-chloro-2,4-dinitrobenzene in the presence of $\mathrm{K}_{2} \mathrm{CO}_{3}$ to give 2. Conversion of 2 to 3 a was achieved by treatment with ethylenediamine to give $3 a^{5 b}$ Treatment of 3a with $p$-toluenesulfonyl chloride in pyridine gave the 5-aminoimidazole-4-carbonitrile derivative $\mathbf{3 b}$. Compounds $\mathbf{3 a}$ and 3b were converted to their 5-iodo derivatives by treatment with isoamyl nitrite in diiodomethane to give $\mathbf{4 a}$ and $\mathbf{4 b}$, respectively. ${ }^{6}$ 


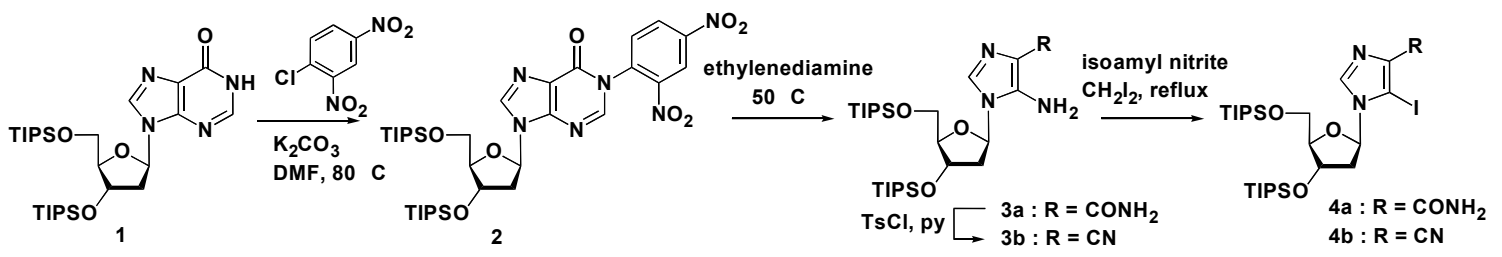

\section{Scheme 1}

\subsection{Synthesis of imidazo[5’,4’:4,5]pyrido[2,3-d]pyrimidine nucleosides}

The synthesis of the diamino derivative ${ }_{\mathbf{i}} \mathbf{N}^{\mathbf{N}}$ was attempted (Scheme 2). When a mixture of the 5-iodoimidazole nucleoside $\mathbf{4 b}$ and the tributylstannyl pyrimidine $5 \mathbf{a}^{4}$ was heated in DMF in the presence of $\mathrm{dba}_{3} \mathrm{Pd}_{2} \quad \mathrm{CHCl}_{3}$, two fluorescent spots corresponding 6 and 7 were detected by TLC analysis. Therefore, treatment of the mixture with $\mathrm{Na}_{2} \mathrm{CO}_{3}$ in aqueous EtOH gave 7, which was further treated with a mixture of 1,4-dioxane and $\mathrm{NH}_{4} \mathrm{OH}$ gave the diamino derivative. Deprotection of the silyl groups with tetrabutylammonium fluoride (TBAF) gave the free nucleoside ${ }_{\mathbf{i}} \mathbf{N}^{\mathbf{N}}$.

Preparation of the dioxo derivative ${ }_{\mathbf{i}} \mathbf{O}^{\mathbf{O}}$ and the amino-oxo derivative ${ }_{\mathbf{i}} \mathbf{N}^{\mathbf{O}}$ was achieved via the Stille coupling reaction between $\mathbf{4 b}$ and $\mathbf{5 b}$. When a mixture of $\mathbf{4 b}$ and $\mathbf{5} \mathbf{b}^{4}$ was heated with $\mathrm{dba}_{3} \mathrm{Pd}_{2} \quad \mathrm{CHCl}_{3}, \mathbf{8}$ was obtained. To convert $\mathbf{8}$ into the dioxo derivative ${ }_{\mathbf{i}} \mathbf{O}^{\mathbf{O}}$, the 4 -cyano group of 8 was hydrolyzed with $\mathrm{H}_{2} \mathrm{O}_{2}$ in the presence of $\mathrm{NH}_{4} \mathrm{OH}$ to give the 4-carboxamide derivative 9. Hydrolytic deamination of the amino group in $\mathbf{9}$ by treatment with isoamyl nitrite in THF containing a small amount of $\mathrm{H}_{2} \mathrm{O}$ gave $\mathbf{1 0}{ }^{7}$ When the resulting $\mathbf{1 0}$ was heated with $\mathrm{NH}_{3} / \mathrm{MeOH}$ in a steel container, the dioxo derivative ${ }_{\mathbf{i}} \mathbf{O}^{\mathbf{O}}$ was obtained after deprotection of the silyl groups. The amino-oxo derivative ${ }_{i} \mathbf{N}^{\mathbf{O}}$ was synthesized also starting from $\mathbf{8}$ using the same procedure, that is, hydrolytic deamination, followed by the intramolecular cyclization and the deprotection.

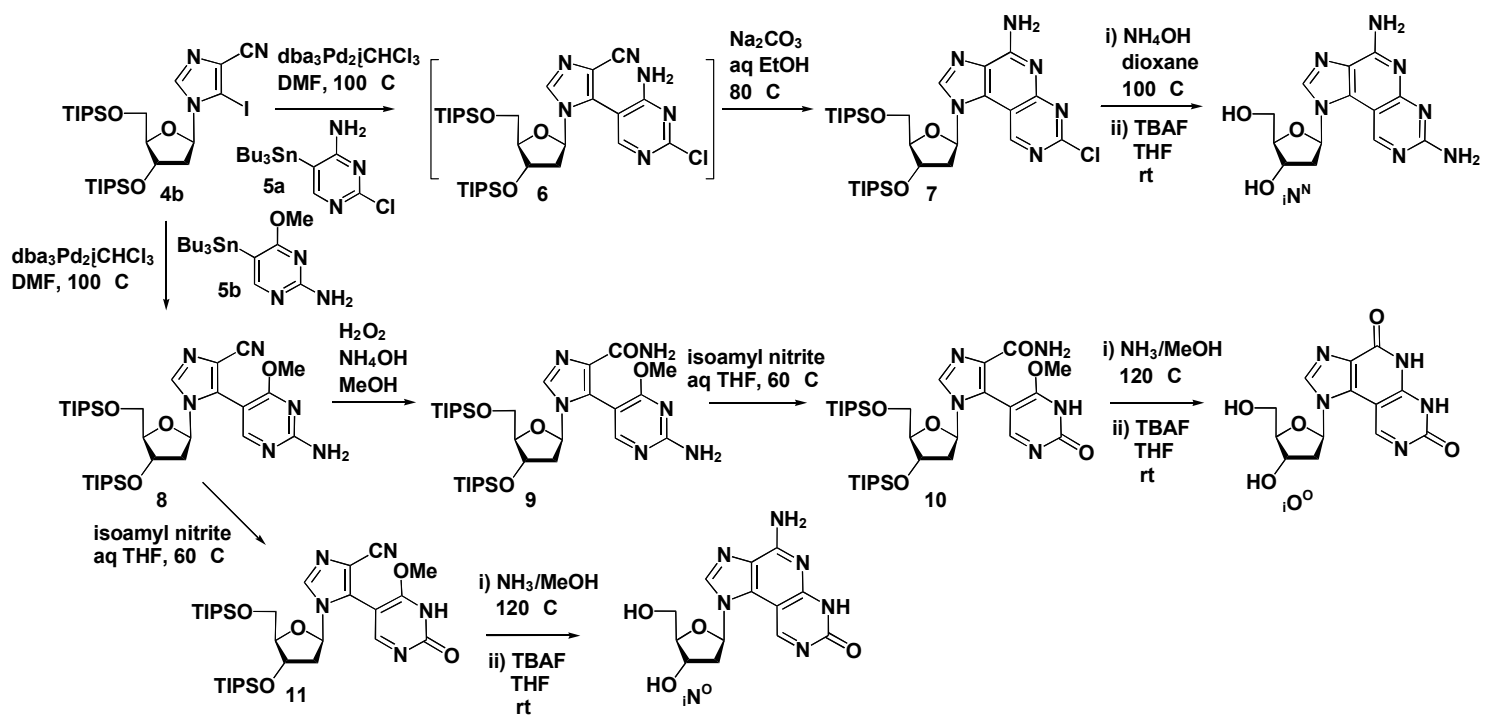

\section{Scheme 2}


The synthesis of the remaining oxo-amino derivative ${ }_{i} \mathbf{O}^{\mathbf{N}}$ was next attempted, which was rather troublesome relative to those of the other tricyclic nucleosides ${ }_{i} \mathbf{N}^{\mathbf{N}},{ }_{i} \mathbf{O}^{\mathbf{O}}$ and ${ }_{\mathbf{i}} \mathbf{N}^{\mathbf{O}}$. The desired ${ }_{i} \mathbf{O}^{\mathbf{N}}$ was thought to be obtained via the intramolecular cyclization of $\mathbf{9}$, using the same method as for ${ }_{\mathrm{i}} \mathbf{O}^{\mathbf{O}}$.
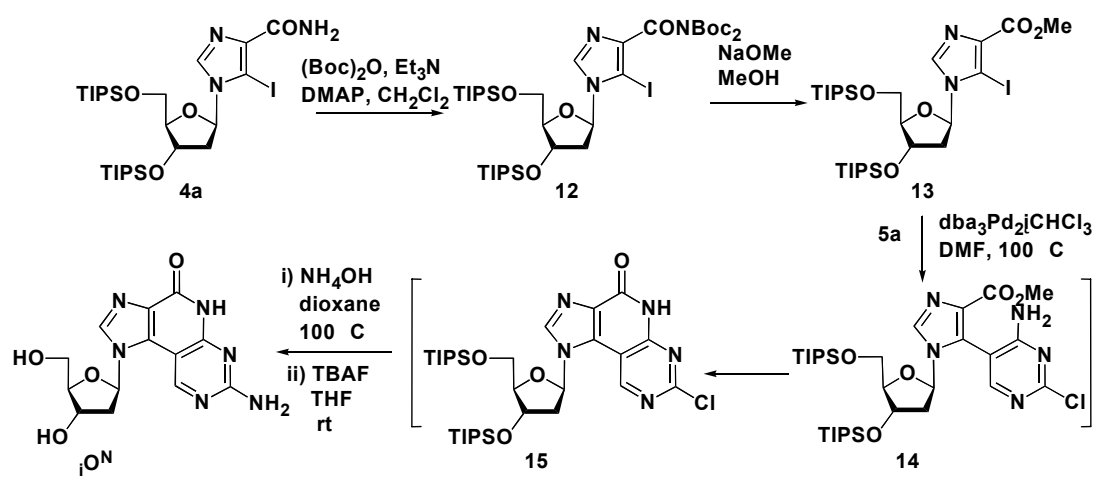

\section{Scheme 3}

However, when 9 was treated $\mathrm{NH}_{3} / \mathrm{MeOH}$ at $120^{\circ} \mathrm{C}$ for $48 \mathrm{~h}$, the desired cyclized product was not obtained, and $\mathbf{9}$ was recovered in quantitative yield. After several attempts, ${ }_{\mathbf{i}} \mathbf{O}^{\mathbf{N}}$ was obtained efficiently as illustrated in Scheme 3. First, the 4-carboxamide group of 4a was converted to the methyl ester according to our previous method. ${ }^{8}$ Thus, treatment of 4 a with di-tert-butyl dicarbonate in the presence of $\mathrm{Et}_{3} \mathrm{~N}$ and DMAP gave 12, which was then treated with $\mathrm{NaOMe}$ in $\mathrm{MeOH}$ to give 13. After the Stille coupling reaction of 13 with $5 \mathrm{a}$ in the presence of $\mathrm{dba}_{3} \mathrm{Pd}_{2}$ $\mathrm{CHCl}_{3}$, the resulting crude products, probably including the intermediates 14 and 15, was treated with a mixture of $\mathrm{NH}_{4} \mathrm{OH}$ and 1,4-dioxane at $100{ }^{\circ} \mathrm{C}$ for $60 \mathrm{~h}$ in a steel container to give the oxo-amino derivative ${ }_{\mathbf{i}} \mathbf{O}^{\mathbf{N}}$ after further deprotection.

\section{Thermal stability of the DNA duplexes containing base pairings between the imidazopyridopyrimidine bases}

To introduce the imidazo[5',4':4,5]pyrido[2,3- $d]$ pyrimidine nucleosides into ODNs by the phosphoramidite method, these nucleosides must be converted into the corresponding phosphoramidites with appropriate protecting groups on each nucleobase. The phosphoramidite units 16, 17, 18, and 19 shown in Figure 3 were used for the synthesis of ODNs. 


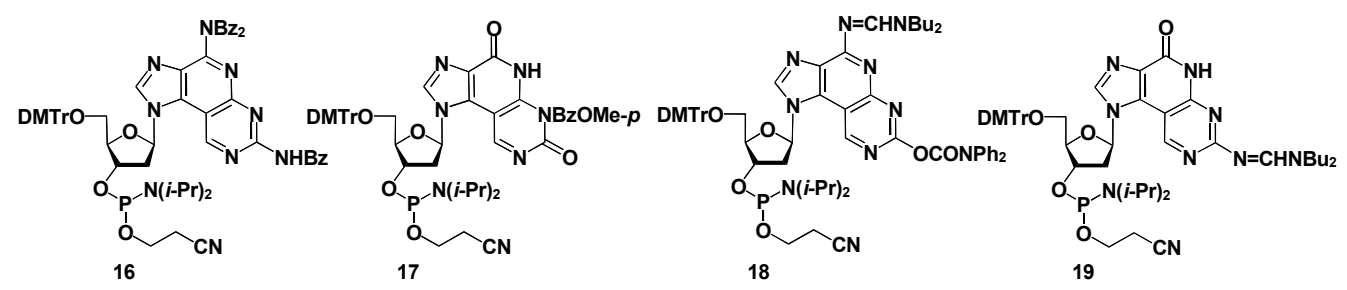

\section{Figure 3}

Thermal stability of duplexes, which contained one molecule of the ${ }_{\mathbf{i}} \mathbf{N}^{\mathbf{N}},{ }_{\mathbf{i}} \mathbf{O}^{\mathbf{O}},{ }_{\mathbf{i}} \mathbf{N}^{\mathbf{O}}$, or ${ }_{\mathbf{i}} \mathbf{O}^{\mathbf{N}}$ in their $\mathbf{X}$ or $\mathbf{Y}$ position, was studied by thermal denaturation in a buffer of $0.01 \mathrm{M}$ sodium cacodylate ( $\mathrm{pH}$ 7.0) containing $0.1 \mathrm{M} \mathrm{NaCl}$ (the left column of Table 1). Each profile of the thermal denaturation showed a single transition corresponding to a helix-to-coil transition to give melting temperatures $\left(T_{\mathrm{m}} \mathrm{s}\right)$.

The melting temperature $\left(T_{\mathrm{m}} \mathrm{s}\right)$ values and their differences from that of A:T pair(s) at the $\mathbf{X}: \mathbf{Y}$ position of the ODN $\left(\Delta T_{\mathrm{m}} \mathrm{s}\right)$ are shown in Table 1. Contrary to our expectation, when one molecule of the tricyclic nucleosides was incorporated into each strand, the thermal stabilities of the duplexes did not increase. The $T_{\mathrm{m}}$ values of the duplexes were all slightly lower than those of the duplexes containing a natural G:C or A:T pair at the corresponding positions, and no apparent specificity of base pairing was observed.

On the other hand, when three molecules of the tricyclic nucleosides were consecutively incorporated into the center of each ODN (the right column of Table 1), the thermal stabilization of the duplexes due to the specific base pairings was observed. The best result was obtained in the case of the duplex containing the ${ }_{\mathbf{i}} \mathbf{N}^{\mathbf{O}}:{ }_{i} \mathbf{O}^{\mathbf{N}}$ pair $\left(T_{\mathrm{m}}=84.0^{\circ} \mathrm{C}\right)$. The value was between 18.2 and $23.5{ }^{\circ} \mathrm{C}$ higher than those of the duplexes containing three consecutive $\mathrm{G}: \mathrm{C}\left(T_{\mathrm{m}}=65.8^{\circ} \mathrm{C}\right)$ and A:T pairs $\left(T_{\mathrm{m}}=60.5^{\circ} \mathrm{C}\right)$, respectively. Consequently, it was found that the ${ }_{\mathrm{i}} \mathbf{N}^{\mathbf{O}}:{ }_{i} \mathbf{O}^{\mathbf{N}}$ pair stabilized the duplex by about +6 and $+8{ }^{\circ} \mathrm{C}$ per modification as compared with those of the duplexes containing the $\mathrm{G}: \mathrm{C}$ and $\mathrm{A}: \mathrm{T}$ pairs, respectively. 
Table 1. Hybridization data of DNA duplexex containing X:Y pair(s)

\begin{tabular}{|c|c|c|c|c|c|c|c|}
\hline \multicolumn{4}{|c|}{$\begin{array}{l}5 \text { ' - GCACCGAAXAAACCACG - } 3 \text { ' } \\
3^{\prime} \text { - CGTGGCTTYTTTGGTGC - } 5 \text { ' }\end{array}$} & \multicolumn{4}{|c|}{$\begin{array}{l}5 \text { ' - GCACCGAXXXAACCACG - } 3 \\
3^{\prime} \text { - CGTGGCTYYYTTGGTGC - } 5\end{array}$} \\
\hline$x$ & $\mathbf{Y}$ & $T_{\mathrm{m}}(\overline{\mathrm{C}})^{\mathrm{a}}$ & $\Delta T_{\mathrm{m}}(\overline{\mathrm{C}})^{\mathrm{b}}$ & $\mathbf{x}$ & $\mathbf{Y}$ & $T_{\mathrm{m}}(\overline{\widetilde{C}})^{\mathrm{a}}$ & $\Delta T_{\mathrm{m}}(\mathbb{C})^{\mathrm{b}}$ \\
\hline \multirow[t]{4}{*}{${ }_{\mathrm{i}} \mathrm{N}^{\mathrm{N}}$} & ${ }_{\mathrm{i}} \mathrm{N}^{\mathrm{N}}$ & 54.5 & Š6.0 & ${ }_{i} \mathrm{~N}^{N}$ & ${ }_{\mathrm{i}} \mathrm{N}^{\mathrm{N}}$ & 55.7 & Š4.8 \\
\hline & $\mathrm{O}^{\circ}$ & 56.3 & Š4.2 & & $\mathrm{O}^{\circ}$ & 70.6 & +10.1 \\
\hline & ${ }_{\mathrm{i}} \mathrm{N}^{\mathrm{O}}$ & 54.5 & Š6.0 & & ${ }_{\mathrm{i}} \mathrm{N}^{\mathrm{O}}$ & 49.4 & Š11.1 \\
\hline & $\mathrm{i}^{\mathrm{N}}$ & 56.1 & Š4.4 & & $\mathrm{i}^{\mathrm{N}}$ & 51.7 & Š8.8 \\
\hline \multirow[t]{4}{*}{$0^{\circ}$} & $\mathrm{i}^{\mathrm{N}}$ & 56.0 & Š 4.5 & $0^{\circ}$ & ${ }_{i} \mathrm{~N}^{\mathrm{N}}$ & 67.1 & +6.6 \\
\hline & $\mathrm{O}^{\circ}$ & 54.3 & Š6. 2 & & $\mathrm{i}^{\circ}$ & 53.5 & Š7.0 \\
\hline & ${ }_{i} \mathrm{~N}^{\mathrm{O}}$ & 54.0 & Š6.5 & & ${ }_{\mathrm{i}} \mathrm{N}^{\mathrm{O}}$ & 58.3 & Š2.2 \\
\hline & $\mathrm{i}^{\mathrm{N}}$ & 54.3 & Š6.2 & & $\mathrm{i}^{\mathrm{N}}$ & 62.3 & +1.8 \\
\hline \multirow[t]{4}{*}{${ }_{\mathrm{i}} \mathrm{N}^{\mathrm{O}}$} & ${ }_{i} \mathrm{~N}^{\mathrm{N}}$ & 55.1 & Š 5.4 & ${ }_{\mathrm{i}} \mathrm{N}^{\mathrm{O}}$ & $\mathrm{i}^{\mathrm{N}}$ & 46.3 & Š 14.2 \\
\hline & $\mathrm{O}^{\circ}$ & 54.0 & Š6.5 & & $0^{\circ}$ & 56.0 & Š4.5 \\
\hline & ${ }_{i} \mathrm{~N}^{\mathrm{O}}$ & 57.2 & Š3.3 & & ${ }_{\mathrm{i}} \mathrm{N}^{\mathrm{O}}$ & 70.0 & +9.5 \\
\hline & $\mathrm{i}^{\mathrm{N}}$ & 59.8 & Š0.7 & & $\mathrm{i}^{\mathrm{N}}$ & 84.0 & +23.5 \\
\hline \multirow[t]{4}{*}{$\mathrm{i}^{\mathrm{N}}$} & $\mathrm{i}^{\mathrm{N}}$ & 55.4 & Š 5.1 & $\mathrm{iO}^{\mathrm{N}}$ & ${ }_{i} \mathrm{~N}^{\mathrm{N}}$ & 41.5 & Š 19.0 \\
\hline & $\mathrm{i}^{\circ}$ & 53.3 & Š7.2 & & $\mathrm{i}^{\circ}$ & 57.5 & Š3.0 \\
\hline & ${ }_{\mathrm{i}} \mathrm{N}^{\mathrm{O}}$ & 58.4 & Š2.1 & & ${ }_{i} \mathrm{~N}^{\circ}$ & 83.8 & +23.3 \\
\hline & $\mathrm{i}^{\mathrm{N}}$ & 56.9 & Š3.6 & & $\mathrm{iO}^{\mathrm{N}}$ & 65.1 & +4.6 \\
\hline $\mathbf{G}$ & C & 61.9 & +1.4 & G & C & 65.8 & +5.3 \\
\hline A & $T$ & 60.5 & 0 & A & $T$ & 60.5 & 0 \\
\hline A & $\mathbf{G}^{\mathrm{c}}$ & 53.8 & Š6.7 & A & $\mathbf{G}^{\mathrm{c}}$ & 47.2 & Š13.3 \\
\hline A & $A^{c}$ & 52.4 & Š8.1 & A & $A^{c}$ & 43.1 & Š17.4 \\
\hline
\end{tabular}

${ }^{\mathrm{a}} 3 \mu \mathrm{M}$ ODN in $0.01 \mathrm{M} \mathrm{Na}$ cacodylate $(\mathrm{pH} 7.0)$ containing $0.1 \mathrm{M} \mathrm{NaCl}{ }^{\mathrm{b}}$ The $\Delta \mathrm{Tm}$ values were obtained by subtracting data for the $T_{m}$ possessing $\mathbf{X}: \mathbf{Y}=\mathrm{A} \cdot \mathrm{T}$ from that for each duplex. ${ }^{\mathrm{c}}$ mismatch.

The order of thermal stabilizing effects of the base-pair when three consecutively incorporated is as follows: $\mathbf{X}: \mathbf{Y}={ }_{\mathrm{i}} \mathbf{N}^{\mathbf{O}}:{ }_{\mathrm{i}} \mathbf{O}^{\mathbf{N}}\left(T_{\mathrm{m}}=84.0{ }^{\circ} \mathrm{C}\right) \geq{ }_{\mathrm{i}} \mathbf{O}^{\mathbf{N}}:{ }_{\mathrm{i}} \mathbf{N}^{\mathbf{O}}\left(T_{\mathrm{m}}=83.8^{\circ} \mathrm{C}\right)>{ }_{\mathrm{i}} \mathbf{N}^{\mathbf{N}}:{ }_{\mathrm{i}} \mathbf{O}^{\mathbf{O}}\left(T_{\mathrm{m}}\right.$ $\left.=70.6^{\circ} \mathrm{C}\right)>{ }_{i} \mathbf{N}^{\mathbf{O}}:{ }_{i} \mathbf{N}^{\mathbf{O}}\left(T_{\mathrm{m}}=70.0^{\circ} \mathrm{C}\right)>{ }_{\mathrm{i}} \mathbf{O}^{\mathbf{O}}:{ }_{i} \mathbf{N}^{\mathbf{N}}\left(T_{\mathrm{m}}=67.1^{\circ} \mathrm{C}\right)>{ }_{\mathrm{i}} \mathbf{O}^{\mathbf{N}}:{ }_{i} \mathbf{O}^{\mathbf{N}}\left(T_{\mathrm{m}}=65.1^{\circ} \mathrm{C}\right)>{ }_{\mathrm{i}} \mathbf{O}^{\mathbf{O}}:{ }_{i} \mathbf{O}^{\mathbf{N}}$ $\left(T_{\mathrm{m}}=62.3^{\circ} \mathrm{C}\right)$. From these data, it could be concluded that the H-bonding abilities between the imidazopyridopyrimidine bases are essential and affect the thermal stability of the duplex. However, a stacking interaction influence, arising from the extended aromatic surface of the imidazopyridopyrimidine bases, may also contribute to their stabilities. ${ }^{9,10}$

Therefore, the stacking ability of the imidazopyridopyrimidine bases were compared with natural nucleobases using self-complimentary ODNs containing an unpaired $\mathbf{Z}$ unit (5'-ZCGCGCG-3'), ${ }^{10}$ in which each tricyclic base or natural base was introduced. The order of the stacking ability $\left(\Delta \Delta G^{\circ}\right)$ was ${ }_{i} \mathbf{N}^{\mathbf{O}}(5.6)>{ }_{i} \mathbf{N}^{\mathbf{N}}(4.2)>{ }_{i} \mathbf{O}^{\mathbf{N}}(3.8)>\mathbf{G}(2.5)>{ }_{i} \mathbf{O}^{\mathbf{O}}(2.4)=\mathbf{A}(2.4)>$ $\mathbf{C}(1.3)>\mathbf{T}(1.0)$. Together with thermal stability and stacking ability data indicated that not only a number of H-bondings, but also stacking ability contributed the thermal stability of the DNA duplexes containing the imidazopyridopyrimidine bases. However, the base pair between the imidazopyrido-pyrimidine would have a similar $\mathrm{C} 1$ '-C1' distance between purine:purine base pairs. The distance in the G (anti):A (anti) mismatch was reported to be $12.5 \AA$, ${ }^{11}$ while that in a canonical Watson-Crick base pair is $10.5( \pm 0.2) \AA .{ }^{12}$ Therefore, we speculated that thermal 
destabilization of the duplex occurs at both sides of these pairs. When one pair of the tricyclic nucleoside was incorporated into the duplex, the destabilization factor arising from disruption of the Watson-Crick base pairs next to the pair would be greater than the stabilization arising from the stable H-bonds. Consequently, the duplex would become less stable (Figure 4A). On the other hand, when the tricyclic nucleosides were consecutively incorporated into the duplex, the duplex would be thermally stabilized to a great extent since the base pairs between the tricyclic nucleosides has stable H-bonds and a strong stacking ability with the adjacent bases. These stabilization factors would be superior to the conformational destabilization around the boundary of the base pairs. (Figure 4B).
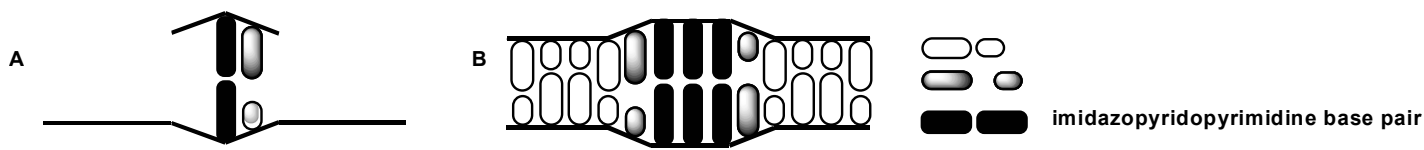

Figure 4. Hypothetical DNA structures.

\section{Designing and synthesis of 1,8-naphthyridine $C$-nucleosides}

The base pair of the imidazopyridopyrimidines markedly stabilized a duplex when three of the pairs were consecutively incorporated into ODNs. However, incorporation of one pair into ODNs resulted in destabilization of the duplex relative to those containing A:T and G:C base pairs. ${ }^{3}$ These results showed shape complementarity resembling a pyrimidine:purine base pair in natural DNA is also important to stabilize DNA duplexes along with a number of H-bonds and base stacking. Since the goal of our continuing study is to develop base pairing motifs which stabilize and regulate DNA structures, including a double helix independent mode of incorporation of the new base pair(s), (i.e., one pair, three nonconsecutive pairs, and three consecutive pairs in this study), the novel 1,8-naphthyridine $C$-nucleosides possessing ${ }_{n} \mathbf{N}^{\mathbf{N}},{ }_{\mathbf{n}} \mathbf{O}^{\mathbf{O}},{ }_{\mathbf{n}} \mathbf{N}^{\mathbf{O}}$, and ${ }_{\mathbf{n}} \mathbf{O}^{\mathbf{N}}$ bases were designed. $^{3,13}$ These $C$-nucleosides are expected to form four sets of naphthyridine: imidazopyridopyrimidine base pairing motifs $\left({ }_{i} \mathbf{N}^{\mathbf{O}}:{ }_{n} \mathbf{O}^{\mathbf{N}},{ }_{\mathbf{i}} \mathbf{O}^{\mathbf{O}}:{ }_{n} \mathbf{N}^{\mathbf{N}},{ }_{i} \mathbf{O}^{\mathbf{N}}:{ }_{n} \mathbf{N}^{\mathbf{O}}\right.$, and ${ }_{i} \mathbf{N}^{\mathbf{N}}:{ }_{n} \mathbf{O}^{\mathbf{O}}$ ) with four H-bonds when these are incorporated into ODNs (Figure 2, $2^{\text {nd }}$ generation). In addition, the new motifs can be regarded as a sort of ring expanded pyrimidine:purine type base pair (possessing $\mathrm{C} 1$ ' $-\mathrm{C} 1$ ' distances similar to the Watson-Crick base pair). Herein, we describe the synthesis of the 1,8-naphthyridine $C$-nucleosides ${ }_{\mathbf{n}} \mathbf{N}^{\mathbf{O}},{ }_{\mathbf{n}} \mathbf{O}^{\mathbf{N}},{ }_{\mathbf{n}} \mathbf{N}^{\mathbf{N}}$ and ${ }_{\mathbf{n}} \mathbf{O}^{\mathbf{O}}$ and the effects on the thermal stabilities of the ODNs containing the naphthyridine $\left({ }_{n} \mathbf{N}^{\mathbf{O}}\right.$ and $\left.{ }_{n} \mathbf{O}^{\mathbf{N}}\right)$ :imidazopyridopyrimidine $\left({ }_{i} \mathbf{O}^{\mathbf{N}}\right.$ and ${ }_{i} \mathbf{N}^{\mathbf{O}}$ ) base pairing motifs. 


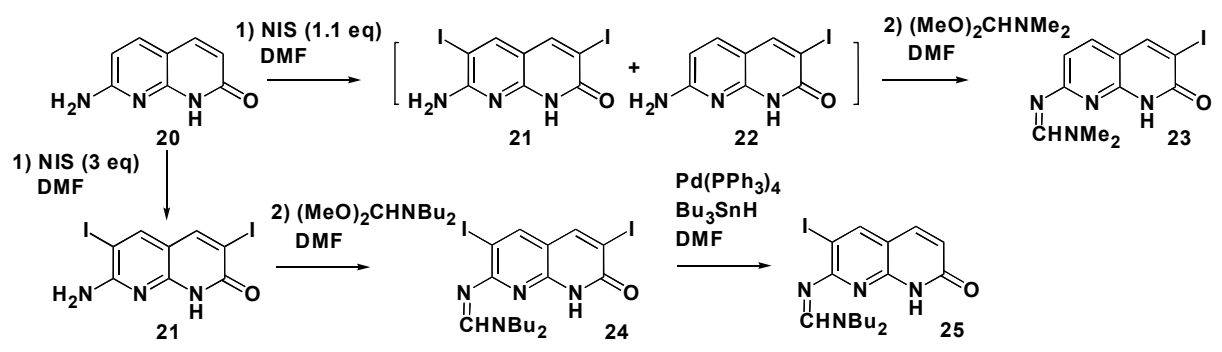

\section{Scheme 4}

The synthetic route to the target compounds is illustrated in Scheme 4. Starting with 2-amino-7-hydroxy-1,8-naphthyridine (20), ${ }^{14}$ iodination by $N$-iodosuccinimide (NIS, 1.1 eq), followed by protection of the exocyclic amino group gave the 6-iodo-1,8-naphthyridine derivative 23, a substrate for the synthesis of ${ }_{\mathbf{n}} \mathbf{N}^{\mathbf{O}}$. For the synthesis of ${ }_{\mathbf{n}} \mathbf{O}^{\mathbf{N}}$, the 3-iodo-1,8-naphthyridine derivative is required. Treatment of $\mathbf{2 0}$ with NIS (3 eq), followed by protection of the exocyclic amino group gave the 3,6-diiodo derivative 24. Conversion of $\mathbf{2 4}$ into the 3-iodo derivative 25 was achieved by treatment of $\mathbf{2 4}$ with a stoichiometric amount of $\mathrm{Bu}_{3} \mathrm{SnH}$ in the presence of $\operatorname{Pd}\left(\mathrm{PPh}_{3}\right)_{4}{ }^{15}$

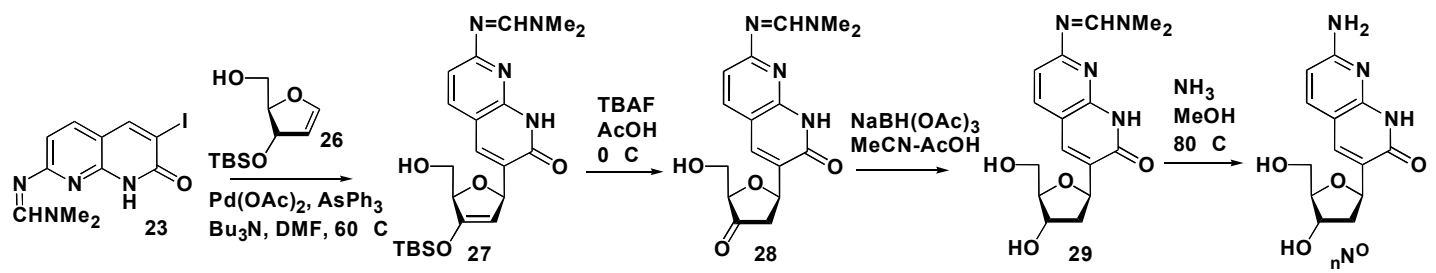

\section{Scheme 5}

After Heck coupling of the 6-iodo derivative 23 with the glycal $\mathbf{2 6}^{16}\left[\mathrm{Pd}(\mathrm{OAc})_{2}, \mathrm{AsPh}_{3}\right.$, tributylamine, DMF], followed by deprotection and reduction, ${ }^{17}$ the desired 29 was obtained (Scheme 5). In the same manner, the reaction of $\mathbf{2 5}$ with $\mathbf{2 6}$ afforded $\mathbf{3 0}$ (Scheme 6).

Treatment of $\mathbf{2 9}$ and 32 with $\mathrm{NH}_{3} / \mathrm{MeOH}$ gave the free nucleosides ${ }_{\mathbf{n}} \mathbf{N}^{\mathbf{O}}$ and ${ }_{\mathbf{n}} \mathbf{O}^{\mathbf{N}}$, respectively. In Scheme 6 , the preparation of the desired ${ }_{n} \mathbf{O}^{\mathbf{O}}$ and ${ }_{n} \mathbf{N}^{\mathbf{N}}$ was also shown. After silylation of $\mathbf{n}^{\mathbf{N}}$, 33 was diazotized with $\mathrm{NaNO}_{2}$ in $\mathrm{AcOH}$ to give 34, which was treated with $\mathrm{NH}_{3} / \mathrm{MeOH}$, followed by deprotection to afford ${ }_{\mathbf{n}} \mathbf{O}^{\mathbf{O}}$. The desired ${ }_{\mathbf{n}} \mathbf{N}^{\mathbf{N}}$ was also prepared from 32. Chlorination of 35 in $\mathrm{POCl}_{3}$ gave 36, which was further treated with $\mathrm{NH}_{3} / \mathrm{MeOH}$ to remove protecting groups both at the sugar and base moieties. The residue was then heated in liq $\mathrm{NH}_{3}$ in a steel container to afford ${ }_{n} N^{N}$. 


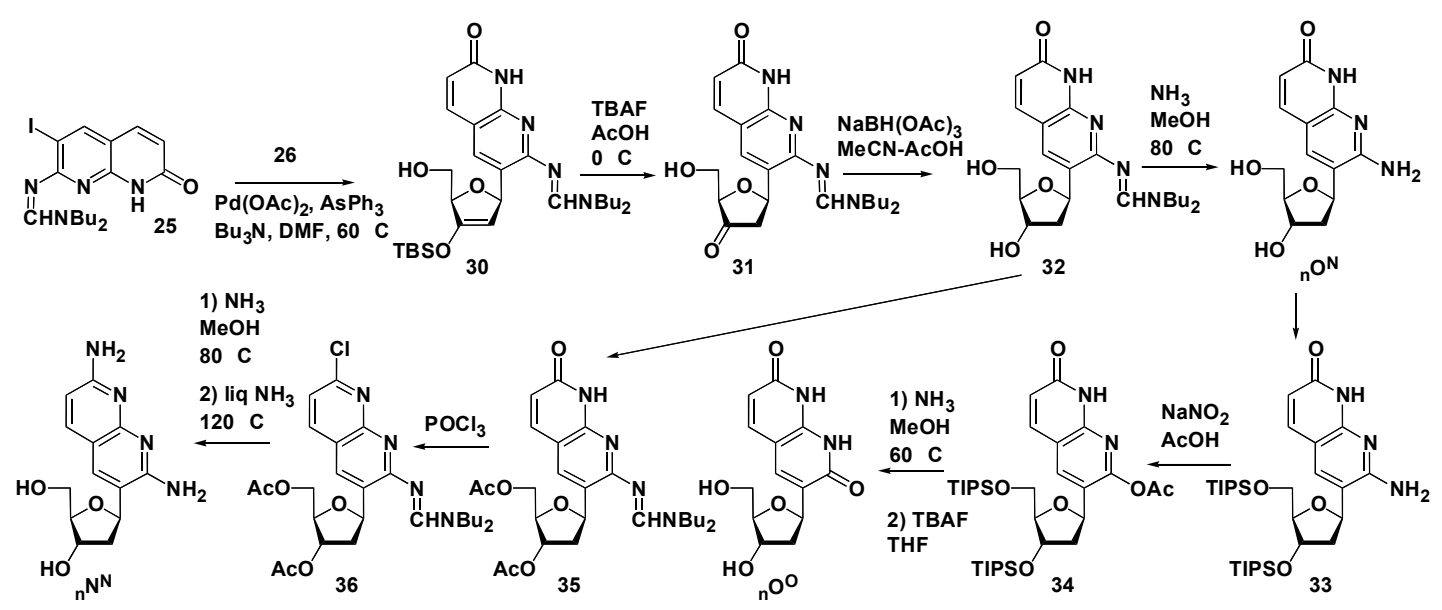

Scheme 6

\section{Thermal stability of the DNA duplexes containing base parings between the naphthyridine and the imidazopyridopyrimidine bases}

To incorporate both of the $C$-nucleosides into ODNs, ${ }_{n} \mathbf{N}^{\mathbf{O}}$ and ${ }_{\mathbf{n}} \mathbf{O}^{\mathbf{N}}$ were converted into the corresponding phosphoramidites $\mathbf{3 8}$ and 39, respectively. For the conversion of ${ }_{\mathbf{n}} \mathbf{O}^{\mathbf{N}}$, the $\mathrm{N}$-benzoyl group was the best choice for the exocyclic amino protecting group, and methyl $N, N$-diisopropylchlorophosphoramidite was used to give 39 because of purification problems when 2-cyanoethyl $N, N$-diisopropylchlorophosphoramidite was used.

\section{Figure 4}
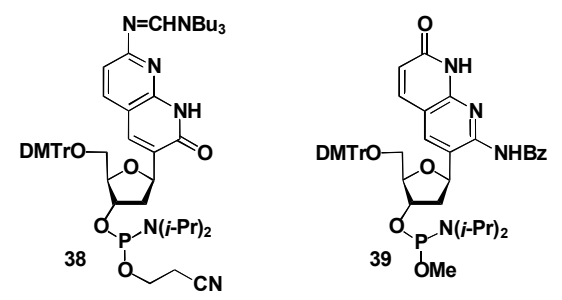

To investigate the base pairing properties of ${ }_{n} \mathbf{N}^{\mathbf{O}}$ and ${ }_{\mathbf{n}} \mathbf{O}^{\mathbf{N}}$, three classes of complementary duplexes were synthesized. As shown in Table 2, the first class contains one $\mathbf{X}: \mathbf{Y}$ pair in the center of the duplexes (duplex 1). The second one contains three nonconsecutive $\mathbf{X}$ :Y pairs (duplex 2), and the last one is made up of three consecutive $\mathbf{X}: \mathbf{Y}$ pairs (duplex 3). The thermal stability of all duplexes was measured by thermal denaturation in a buffer of $10 \mathrm{mM}$ sodium cacodylate $(\mathrm{pH} 7.0)$ containing $0.001 \mathrm{M} \mathrm{NaCl}$, since in a buffer containing $0.1 \mathrm{M} \mathrm{NaCl}$, some duplexes showed $T_{\mathrm{m}} \mathrm{s}$ higher than $95^{\circ} \mathrm{C}$.

As we expected, the pairs of ${ }_{i} \mathbf{O}^{\mathbf{N}}{ }_{n} \mathbf{N}^{\mathbf{O}}$ and ${ }_{i} \mathbf{N}^{\mathbf{O}}:{ }_{n} \mathbf{O}^{\mathbf{N}}$ stabilized the duplex 1 by $+9.4{ }^{\circ} \mathrm{C}$ and $+8.6{ }^{\circ} \mathrm{C}$, respectively. Although the ${ }_{\mathbf{n}} \mathbf{N}^{\mathbf{O}}:{ }_{\mathbf{n}} \mathbf{O}^{\mathbf{N}}$ pair stabilized the duplex by $+2.3{ }^{\circ} \mathrm{C}$, the ${ }_{\mathbf{i}} \mathbf{O}^{\mathbf{N}}:{ }_{i} \mathbf{N}^{\mathbf{O}}$ pair destabilized the duplex as described above by $-3.8^{\circ} \mathrm{C}$. The pronounced effects by ${ }_{i} \mathbf{O}^{\mathbf{N}}:{ }_{n} \mathbf{N}^{\mathbf{O}}$ 
and ${ }_{i} \mathbf{N}^{\mathbf{O}}:{ }_{n} \mathbf{O}^{\mathbf{N}}$ were emphasized in the duplex 2 . Both pairs stabilized the duplexes by more than $+30{ }^{\circ} \mathrm{C}$, while the effects of ${ }_{i} \mathbf{O}^{\mathbf{N}}:{ }_{i} \mathbf{N}^{\mathbf{O}}$ and ${ }_{\mathbf{n}} \mathbf{N}^{\mathbf{O}}{ }_{n} \mathbf{O}^{\mathbf{N}}$ were insufficient despite the expected base pairing motifs with four H-bonds. In the duplex 3 , not only the ${ }_{\mathbf{i}} \mathbf{O}^{\mathbf{N}}:{ }_{n} \mathbf{N}^{\mathbf{O}}$ and ${ }_{i} \mathbf{N}^{\mathbf{O}}{ }_{{ }_{n}} \mathbf{O}^{\mathbf{N}}$ pairs but also the ${ }_{\mathbf{i}} \mathbf{O}^{\mathbf{N}}:{ }_{\mathbf{i}} \mathbf{N}^{\mathbf{O}}$ and ${ }_{\mathbf{n}} \mathbf{N}^{\mathbf{O}}:{ }_{\mathbf{n}} \mathbf{O}^{\mathbf{N}}$ pairs stabilized the duplexes much more than $\mathrm{G}: \mathrm{C}$ and A:T pairs, although the first pairs are generally considered more effective for thermal stability. From these results, it was concluded that the newly designed ${ }_{i} \mathbf{O}^{\mathbf{N}}:{ }_{n} \mathbf{N}^{\mathbf{O}}$ and ${ }_{i} \mathbf{N}^{\mathbf{O}}:{ }_{n} \mathbf{O}^{\mathbf{N}}$ base pairs thermally stabilized the duplex by nearly $10^{\circ} \mathrm{C}$ more per pair than the A:T pair and $8{ }^{\circ} \mathrm{C}$ more than the G:C pair independent mode of incorporation of the new base pair(s) into the ODNs.

Table 2. Hybridization data of DNA duplexes containing X:Y pair(s)

\begin{tabular}{|c|c|c|c|c|}
\hline duplex & $x$ & $Y$ & $T_{m}(\bar{C} \mathrm{C})^{a}$ & $\Delta T_{\mathrm{m}}(\overline{\mathrm{C}} \mathrm{C})^{\mathrm{b}}$ \\
\hline & $\mathrm{i}^{\mathrm{N}}$ & ${ }_{n} \mathrm{~N}^{0}$ & 57.2 & +9.4 \\
\hline duplex 1 & ${ }_{\mathrm{i}} \mathrm{N}^{\mathrm{O}}$ & ${ }_{n}^{n} \mathrm{O}^{N}$ & 56.4 & +8.6 \\
\hline \multirow{4}{*}{$\begin{array}{l}5 \text { ' - GCACCGAAXAAACCACG - } 3 \text { ' } \\
3 \text { ' - CGTGGCTTYTTTGGTGC - } 5 \text { ' }\end{array}$} & $\mathrm{i}^{\mathrm{N}}$ & $\mathrm{i}^{\mathrm{NO}}$ & 44.0 & Š3.8 \\
\hline & ${ }_{n} \mathrm{~N}^{0}$ & $\mathrm{n}^{\mathrm{N}}$ & 50.1 & +2.3 \\
\hline & G & C & 49.1 & +1.3 \\
\hline & A & $T$ & 47.8 & 0 \\
\hline \multirow{5}{*}{$\begin{array}{l}\text { duplex } 2 \\
5^{\prime} \text { - GCXCCGAAXAAACCXCG - } 3 \text { ' } \\
3^{\prime} \text { - CGYGGCTTYTTTGGYGC - } 5 \text { ' }\end{array}$} & $\mathrm{O}^{\mathrm{N}}$ & $\mathrm{n}^{\mathrm{N}^{\circ}}$ & 82.2 & +34.4 \\
\hline & $\mathrm{i}^{\mathrm{N}}$ & $\mathrm{n}^{\mathrm{N}}$ & 80.9 & +33.1 \\
\hline & $\mathrm{O}^{\mathrm{N}}$ & ${ }_{\mathrm{i}}^{1} \mathrm{~N}^{\mathrm{O}}$ & 53.3 & +5.5 \\
\hline & ${ }_{n} \mathrm{~N}^{\circ}$ & $\mathrm{nO}^{\mathrm{N}}$ & 48.9 & +1.1 \\
\hline & G & $C$ & 56.7 & +8.9 \\
\hline \multirow{5}{*}{$\begin{array}{l}\text { duplex } 3 \\
5^{\prime}-\text { GCACCGAXXXAACCACG - } 3 \text { ' } \\
3^{\prime} \text { - CGTGGCTYYYTTGGTGC - } 5 \text { ' }\end{array}$} & $\mathrm{O}^{\mathrm{N}}$ & $\mathrm{n}^{\mathrm{NO}}$ & 80.2 & +32.4 \\
\hline & ${ }_{\mathrm{i}} \mathrm{N}^{\mathrm{O}}$ & ${ }_{n} \mathrm{O}^{N}$ & 81.0 & +33.2 \\
\hline & $\mathrm{i}^{\mathrm{N}}$ & ${ }_{\mathrm{i}} \mathrm{N}^{\mathrm{O}}$ & 70.4 & +22.6 \\
\hline & ${ }_{n} \mathrm{~N}^{0}$ & ${ }_{n} \mathrm{O}^{N}$ & 68.1 & +20.3 \\
\hline & G & C & 55.2 & +7.4 \\
\hline
\end{tabular}

a $3 \mu \mathrm{M}$ ODN in $0.01 \mathrm{M} \mathrm{Na}$ cacodylate ( $\mathrm{pH} 7.0$ ) containing $\mathbf{0 . 0 0 1} \mathbf{M} \mathbf{~ N a C l} .{ }^{\mathrm{b}}$ The $\Delta \mathrm{Tm}$ values were obtained by subtracting data for the $T_{m}$ possessing $\mathbf{X}: \mathbf{Y}=\mathrm{A} \cdot \mathrm{T}$ from that for each duplex.

This effect is presumably caused by the four H-bonds and the stacking effect of the expanded aromatic surfaces with shape complementarity to a pyrimidine:purine base pair (Figure 5). Although some shift in the base pairing phase from the usual pyrimidine:purine base pairing would occur to complete the base pairing of ${ }_{i} \mathbf{O}^{\mathbf{N}}:{ }_{n} \mathbf{N}^{\mathbf{O}}$ and ${ }_{i} \mathbf{N}^{\mathbf{O}}{ }_{n} \mathbf{O}^{\mathbf{N}}$ (see Figure 2), the effect of this shift should be negligible for the thermally stable duplex formation since both pairs stabilized the duplex independent mode of incorporation.

In conclusion, the ODNs containing the base pairing motifs ${ }_{\mathbf{i}} \mathbf{O}^{\mathbf{N}}:{ }_{\mathbf{n}} \mathbf{N}^{\mathbf{O}}$ and ${ }_{\mathbf{i}} \mathbf{N}^{\mathbf{O}}:{ }_{\mathbf{n}} \mathbf{O}^{\mathbf{N}}$ formed extremely thermally stable duplexes by cooperative effects of the four H-bonds, the stacking effects and shape complementarity. In addition, these motifs are specific, so that these would be versatile in stabilizing and regulating a variety of DNA structures.
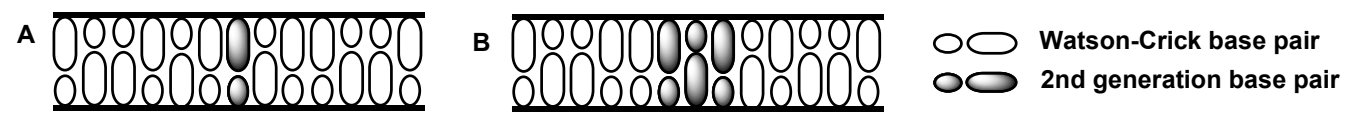

Figure 5. Hypothetical DNA structures. 


\section{References}

1. Recent reviews, see: (a) Lilley, D. M. J. In Bioorganic Chemistry: Nucleic Acids; Hecht, S. M., Ed.; Oxford University Press: Oxford, 1996; Chapter 7, pp 186-215. (b) Belmont, P.; Constant, J. -F.; Demeunynck, M. Chem. Soc. Rev. 2001, 30, 70-81.

2. Recent reviews, see: (a) Benner, S. A. Acc. Chem. Res. 2004, 37, 784. (b) Geyer, C. R.; Battersby, T. T.; Benner, S. A. Structure 2003, 11, 1485. (c) Benner, S. A. Science 2004, 306, 625.

3. Minakawa, N.; Kojima, N.; Hikishima, S.; Sasaki, T.; Kiyosue, A.; Atsumi, N.; Ueno, Y.; Matsuda, A. J. Am. Chem. Soc. 2003, 125, 9970.

4. Hikishima, S.; Minakawa, N.; Kuramoto, K.; Fujisawa, Y.; Ogawa, M.; Matsuda, A. Angew. Chem. Int. Ed. 2005, 44, 596.

5. (a) Minakawa, N.; Sasabuchi, Y.; Kiyosue, A.; Kojima, N.; Matsuda, A. Chem. Pharm. Bull. 1996, 44, 288. (b) Napoli, L. D.; Messere, A.; Montesarchio, D.; Piccialli, G.; Varra, M. J. Chem. Soc., Perkin Trans. 1 1997, 2079.

6. (a) Minakawa, N.; Takeda, T.; Sasaki, T.; Matsuda, A.; Ueda, T. J. Med. Chem. 1991, 34, 778.

(b) Minakawa, N.; Matsuda, A. Tetrahedron 1993, 49, 557. (c) Matsuda, A.; Shinozaki, M.; Yamaguchi, T.; Homma, H.; Nomoto, R.; Miyasaka, T.; Watanabe, Y.; Abiru, T. J. Med. Chem. 1992, 35, 241.

7. Nair, V.; Chamberlain, S. D. Synthesis 1984, 401.

8. Kojima, N.; Minakawa, N.; Matsuda, A. Tetrahedron 2000, 56, 7909.

9. For examples: (a) Lin, K.-Y.; Jones R J.; Matteucci M. J. Am. Chem. Soc. 1995, 117, 3873. (b) Brotschi, C.; Haberli, A.; Leumann, C. J. Angew. Chem. Int. Ed. 2001, 40, 3012. (c) Hashmi, S. A. N.; Hu, X.; Immoos, C. E.; Lee, S. J.; Grinstaff, M, W. Org. Lett. 2002, 4, 4571.

10. Guckian, K. M.; Schweitzer, B. A.; Ren, R. X.-F.; Sheils, C. J.; Paris, P. L.; Tahmassebi, D. C.; Kool, E. T. J. Am. Chem. Soc. 1996, 118, 8182.

11. Privé, G. G.; Heinemann, U.; Chandrasegaran, S.; Kan, L.-S.; Kopka, M. L.; Dickerson, R. E. Science 1987, 238, 498.

12. Coté, M. L.; Georgiadis, M. M. Acta. Cryst. 2001, D57, 1238.

13. (a) Eldrup, A. B.; Nielsen, B. B.; Haamia, G.; Rasmussen, H.; Kastrup, J. S.; Christensen, C.; Nielsen, P. E. Eur. J. Org. Chem. 2001, 1781. (b) Eldrup, A. B.; Christensen, C.; Haamia, G.; Nielsen, P. E. J. Am. Chem. Soc. 2002, 124, 3254.

14. Newkome, G. R.; Garbis, S. J.; Majestic, V. K.; Fronczek, F. R.; Chiari, G. J. Org. Chem. 1981, 46, 833.

15. Kim, W. -S.; Kim, H. -J.; Cho, C. -G. J. Am. Chem. Soc. 2003, 125, 14288.

16. Coleman, R. S.; Madaras, M. L. J. Org. Chem. 1998, 63, 5700.

17. Zhang, H. -C.; Daves, Jr., G. D. J. Org. Chem. 1992, 57, 4690. 